\title{
ABSTRACT
}

Based on the review of some selected literatures, this article attempts to explain Urban Anthropology as an emerging sub-field within Sociocultural Anthropology. In this process, it reviews the history of the subfield in short and elaborates its field of scope in the modern rapidly urbanizing world. Definitely, the process of urbanization has also been given adequate emphasis by highlighting its concept and nature. Even the status of urbanization in Nepal has also been given place in brief. The article towards the latter part explains about the prospects of Urban Anthropology in Nepal.

KEY WORDS: Urbanization, Urban Anthropology, Anthropology of the City, Anthropology in the City and Nepal

\section{CONCEPT OF URBANIZATION}

Urbanization characterizes the recent development in human culture. It has been perceived and explained by different scholars in different ways reflecting the domain and interest of their concerned disciplines. Champion (2001) asserts that "some have conceived of urbanization in the physical sense of the increasing area of land being developed for urban use, while others view urbanization as a social process of people adopting the attitudes and behaviour traditionally associated with life in cities and towns, irrespective of where they might be living." Some of the scholars define it in demographic sense as congregation of people in a definite territory; some perceive it in physical sense as the transformation of a rural setting into an urban one while others perceive as occupational shift and means of economic transformation. But most of the scholars share the common view that it resembles the highest level of socio-cultural evolution that human beings have attained to date.

According to Orum (2004), "Urbanization is the process whereby large numbers of people congregate and settle in an area, eventually 
developing social institutions, such as businesses and government, to support themselves. Urban areas, or those pockets of people and institutions thereby created, are generally characterized as relatively dense settlements of people. Furthermore, it is claimed, they sometimes originate from the effort by authorities to consciously concentrate power, capital, or both at a particular site."

Urbanization is important from the socio-cultural evolution point of view too. A rural setting gradually loses its rural features as they are evolved into or replaced by the urban ones and hence become more developed and civilized. Thus, some scholars even equate the process of urbanization with civilization. Smart and Smart (2003) consider urbanization to include not only the growth of cities, but also the transformation of existing urban places. Similarly, in the words of Roberts and Kanaley (2006); "Urbanization - the spatial concentration of people and economic activity- is arguably the most important social transformation in the history of civilization since man changed from being a nomadic hunter-gatherer and adopted a settled, subsistence agricultural way of life. While the timing and speed of urbanization have varied and are varying between countries, regions, and continents, the urbanization process has taken hold everywhere. It has proven to be an unstoppable and a mostly desirable phenomenon. Cities are the foundation of modern civilization; they are the engine room of economic growth and the centers of culture, entertainment, innovation, education, knowledge, and political power."

As the process of urbanization intensifies, there occurs a shift in what are called rural features of a socio-cultural setting. Occupation shift, production-related shift, higher level of population etc. are some of the examples of such changes in a rural society. Similarly there occurs a distinct change in micro-social institutions like marriage, family and kinship and communal feelings with the rise of individualistic feeling among the people. In this context citing Kumar (2003) becomes quite relevant who expresses that "Urbanization is the directed concentration of population in urban space. The city itself becomes a narrative device for understanding the process of urbanization. The continually changing tempo of urbanization is not the outcome of a natural order of things, but rather a consciously directed human action. With urbanization, 
people moved from rural to urban residences, with an accompanying shift from agricultural to industrial occupations. A sense of community in these urban spaces became vastly different from rural models that were based on kinship networks and traditions. The fast pace of city life and the frequently competitive existence of urban dwellers make it far more difficult to connect with the community."

Therefore, urbanization is the process whereby large numbers of people concentrate and settle in an area, ultimately developing social institutions, such as businesses, trade and government, to support themselves. Urbanization further includes the expansion of cities into surrounding communities like suburbs and regions. The perception and concept of urbanization largely depends on the interest of the discipline and the concerned. But what is common in almost all scholars is the view that it is a developmental process. Now it has become ubiquitous, too. It reflects the highest level of civilization that humans have experienced so far. S,o improvement in the quality of life of people has to be preferred over-looking at the increase in population for conceptualizing and explaining the fact of urbanization.

\section{URBANIZATION IN NEPAL : A GLIMPSE}

Urbanization process has been intensifying throughout the world in the recent years and Nepal is no more an exception. Rural to urban migration is happening at a faster rate and the number of urban, urbanizing and semi urban areas are increasing throughout the country. Some areas are exhibiting a spontaneous process of urbanization while other are forcefully declared as urban areas by the Government in the name of municipalities. Officially, the Government of Nepal has declared 58 urban and semi urban areas as municipal areas: 53 of them being municipalities, 4 sub-metropolises and 1 metropolis. According to Portnov et.al. (2007) "Currently, 58 municipalities in Nepal qualify as urban centers. Five-Kathmandu, Lalitpur, Biratnagar, Pokhera and Birgunj-have more than 100000 inhabitants; the population of 11 others ranges from 50000 to 100000 residents; 22 towns have 25000 to 50000 residents, while the 20 smallest towns have less than 25000 residents." 
is characterized by a rapid growth of small and medium-sized urban centres, most of which are situated in the Terai flatland in the south of the country along the East-West Highway. But the urban centres are located not-only in Teari region but also in Hilly and Mountain Region. The Nepalese Government has declared areas with relatively less infrastructure also as municipalities which consequently have given rise to number of problems. Historical data show urbanization as an ever increasing process in Nepal as the population of designated urban areas is found to be increasing in each census report. As per the record of Census of 2001, the urban population in Nepal is 14.20 percent (CBS, 2003). But this figure includes the population of designated urban areas only and does not give the exact population of all urban centers in Nepal.

Most of the urban areas in Nepal have been the symbolizing unplanned and unmanaged settlements. As a result, we can see more and more sufferings of a multifarious nature among the urban dwellers of our country. Ertur further criticizes urbanization processes in Nepal by saying: "Urban areas and towns lack basic infrastructure services. Safe drinking water supplies and electricity are inadequate in urban areas and towns, a situation that is endemic nationwide. There is virtually no sanitary waste disposal system, and solid waste systems are extremely inadequate. Urban road conditions are dilapidated. None of the urban areas has a functioning storm-water drainage system (1994:19)."

Therefore, there is an urgent need of developing a systematic townplanning system in order to solve the problems arisen due to unmanaged urbanization in Nepal. Since municipalities are regarded as the major urban areas, in part of government, the declaration of municipality should be done only after installing basic urban amenities.

\section{URBAN ANTHROPOLOGY: CONCEPTUAL OVERVIEW}

There are a number of sub-fields developed within Socio-Cultural Anthropology. Medical Anthropology, Ecological Anthropology, Legal Anthropology, Environmental Anthropology, Economic Anthropology, etc. represent some of such subfields. Urban Anthropology is one of the recent developed sub-fields of Socio-Cultural Anthropology. According to Kemper and Rollwagen, "At the simplest level, Urban Anthropology 
is what urban anthropologists do. While some anthropologists do research in particular cities, they do so without much, if any, concern for the urban context; others are concerned with the structure of city life and its impact on human behavior locally or cross-culturally; and still others are concerned with the development of international urban systems through time and space as distinctive social-cultural and political-economic domains. The focus of field research is usually on relatively small populations (e.g., people from one village who have migrated to a city, the culture of one ethnic population of one city, female members of one gang in one city). Urban anthropologists then describe and explain why a particular population behaves as it does (1996:1337).'

Urban Anthropology marks a distinct divergence from the traditional anthropological orientation while focusing the more civilized urbanites of the cities. With this shift in focus, "Urban Anthropology" counters Anthropology's traditional emphasis on "primitive" and peasant people to the exclusion of urban, complex and industrial societies (Basham 1978). Kemper and Rollwagen further explain about the domain of Urban Anthropology stating: "In more theoretical terms, Urban Anthropology involves the study of the cultural systems of cities as well as the linkages of cities to larger and smaller places and populations as part of a worldwide urban system. Thus, Urban Anthropology emphasizes ethnographic research on the cultural systems of selected populations, compares the cultural systems of these populations, and offers contextual explanations for the attitudes and behaviors observed among these populations (1996:1337).'

Urban Anthropology is focused more on the detailed and systematic study of the cultural systems of the cities. For this, it uses Anthropology's key method of ethnography. Conducting ethnographic studies of various cultural groups of cities is obviously a tricky and challenging affair, and Urban Anthropology is getting maturity in this complex field of scope. Kemper (1996) uses a different way for presenting his idea regarding the concept and mission of Urban Anthropology stating that "From the perspective of urban anthropologists, Urban Anthropology is neither a new 'pop' field added to traditional Anthropology nor does it intend to neglect less complex societies. On the contrary, it aims to 
Urban Anthropology...... Bhandari

rehabilitate the so-called 'primitive'. In this way, Urban Anthropology differentiates itself from colonial Anthropology, which assumed that 'primitive' people are essentially different from 'Western civilization'.'

Within Urban Anthropology also we may find a debate between Anthropology of the city and the Anthropology in the city. As Angelini (2009) puts that Anthropology of the city analyzes how urban form and processes are shaped by diverse political, economic, and cultural forces. Study in the city provides descriptive accounts and involves refinement of social scientific concepts to bring them closer to the daily entanglements of urban life. Whether one uses Anthropology of the City or Anthropology in the City in research or academic discussions, Urban Anthropology has been the ultimate beneficiary of the debate as it has helped the discipline to expand further.

\section{BRIEF EARLY HISTORY OF URBAN ANTHROPOLOGY}

Urban Anthropology emerged as a sub-field of Socio-Cultural Anthropology after 1960s, but is has its historical roots in Urban Sociology. As Sajnek (1996) puts "The most important were in the University of Chicago sociological tradition of research into the neighborhoods and institutions of that city initiated by Robert Park after World War I" (Hannerz 1980). But soon after, it appears to have diverged markedly from the urban Sociology but not completely detached as the lines between the two fields have blurred with the exchange of ideas and methodology, to the benefit and advancement of both disciplines.

UrbanAnthropology "crept up" gradually and was almost unnoticed until the late 1960s and the early 1970s. Its roots lie more in the sociological study of industrial societies than in traditional Anthropology. Therefore, early sociologists were the first to turn their attention towards urban life. From the 1930 s to the 1950 s, cultural anthropologists' interest in the study of peasants and the impact of cities on their lives increased (Redfield, 1947). By the 1950s, a number of anthropologists were already conducting research on urban phenomena (Childe 1950, Bott 1957, Sjoberg 1960). The expansion of Urban Anthropology in the 1960 s reflects the recognition that traditional target groups, such as tribal and peasant people, became increasingly integrated into the urbanized 
world. Particular attention was given to rural-urban migration, urban adaptation, ethnicity, and poverty (Lewis 1968, Hannerz 1969) (Cited in Al-Zubaidi, n.d.).

Kemper and Rollwagen (1996) mention that by the end of the 1950s, anthropologists and other social scientists were combining ethnographic observations drawn from specific case studies with national level census data to develop new ideas about trends in urbanization in Latin America, Africa, and Asia. Among the various individual scholars who contributed to lay the foundations for what Urban Anthropology has become today (i.e. the study of the city conceived as a community) was the sociologist Louis Wirth. His essay "Urbanism as a Way of Life" proved to be essential in distinguishing urbanism as a unique form of society that could be studied from three perspectives: "a physical structure, as a system of social organization, and as a set of attitudes and ideas" (Basham, 1978)

Each decade after 1960s, the discipline saw a tremendous growth of its scope as a number of scholars from various world started to get attracted towards it. Not only the number of scholars increased, there was a significant upsurge in the field of Urban Anthropology, thus, expanding its horizon. More and more urban issues started to come under the lens of urban anthropologists across the world in terms of researches and studies. Such researches and studies came not only from USA but also from different parts of the world such as Europe, Latin America, Africa and, though in small number, from Asia. Not only researches were conducted but also there increased the number of publications relating to the discipline of Urban Anthropology. Articles, journals and even handbooks started to appear in the public.

\section{SCOPE OF URBAN ANTHROPOLOGY}

Traditionally, Anthropology was understood as the study of simple societies. Anthropologists were thought as the scholars with particular interest in ethnographic studies of isolated primitive societies. The study of western urban civilized, industrialized societies was believed to be the domain of Sociology while the study of primitive people, rural or village social life was left in the field of Anthropology. But this 
historical distinction of the scope of Sociology and Anthropology started to weaken from the latter half of the $20^{\text {th }}$ century when anthropologists started to turn their attention towards urban socio-cultural lives and associated dynamics.

While "Western civilization" inspired theories on the dynamic forces of modernization and change, "primitive culture" was conceived as stagnant in place and time. This rift in perception generated and reflected the division of labor between Anthropology and Sociology: the study of "Western civilization" and the industrialized world was reserved for the field of Sociology, while the analysis of "primitive cultures" ceded to Anthropology. Thus, the emergence of Urban Anthropology resulted in part from the consequences of World War II and the processes of decolonization. From the perspective of urban anthropologists, the interest in cities has reaffirmed the traditional claim of Anthropology to concern itself with a variety of human cultures and societies. Hence, they do not find the classification of Anthropology as a field that studies "primitives" and Sociology as a field that focuses on industrial societies justifiable. For, in their view, differentiating "the West" as industrial and "the rest" as "primitive" does not constitute a valid opposition because a society does not exist that has not been profoundly touched by industrialization. Theoretically, Urban Anthropology involves the study of the cultural systems of cities as well as the linkages of cities to larger and smaller places and populations as part of the world-wide urban system (Kemper 1996).

Obviously, the shift of main attention of Anthropology from a primitive society to complex urban societies demanded a great transformation in the field and method of traditional Anthropology. This was more crucial as urban socio-cultural life had a great variation as compared to the rural one. In this context Angelini (2000) states that "the term Urban Anthropology came to designate a subfield of cultural Anthropology in the 1960s, even though anthropologists have been conducting research in cities since the 1930s. While ethnography, the core methodological tradition of Anthropology, derives from in-depth studies of rural and village life, the development of Urban Anthropology also reflects broader conceptual debates within the discipline. New conceptualizations of the city have influenced how anthropologists 
think about culture and social change. However, the particular methods and perspectives deployed by anthropologists generate new ways to understand the dynamics of urban life, as well."

Today, Urban Anthropology distinguishes itself from urban Sociology mainly in terms of a different perspective: while sociological studies are more focused on fragmented issues, Urban Anthropology is theoretically rather directed toward a holistic approach (Ansari and Nas 1983: 2). Whereas Urban Anthropology in the 1960s and 70s focused on particular issues such as migration, kinship, and poverty, derived from (or in contrast to) traditional-based fieldwork, urban anthropologists had, by the 1980s, expanded their interests to any aspect of urban life. As a result, Urban Anthropology became more integrated into the discourse of the other social sciences (Al-Zubaidi, n.d.).

According to Richard G. Fox (1977), different research traditions within Urban Anthropology maintain continuity with traditional Anthropology and its methods by not focusing on urbanism itself, but on smaller units within cities. One example is the Anthropology of urban poverty. Oscar Lewis introduced the term "culture of poverty," which he understood as a form of life that exists independently of economical and political deprivation. Naturally, this evoked a series of critiques (Al-Zubaidi, n.d.).

Urban Anthropology has been largely merged with geography, ecology, and other disciplines. Along with a theoretical interest in and conceptualization of urban space and urbanism, contemporary issues of Urban Anthropology include rural-urban migration, demography, adaptation and adjustment of humans in densely populated environments, the effects of urban settings upon cultural pluralism and social stratification, social networks, the function of kinship, employment, the growth of cities, architecture, crime (and other urban dilemmas), and practical urban problems such as housing, , transport, use of space, waste management, and infrastructure.

Kemper and Rollwagen present the method, concept and field of contemporary Urban Anthropology as "Whereas the efforts of urban anthropologists in the 1960s and 1970s were focused on issues (e.g., 
migration, family and kinship, social networks, poverty, ethnicity, and urban adaptation) derived from or contrasted with traditional ruralbased fieldwork, by the 1980s anthropologists had expanded their interests to include virtually every dimension of urban life-from individual life stories to city neighborhoods and institutions (e.g., hospitals, schools, jails) to linkages among places and populations of different scales within the overall urban system. Anthropologists began explicitly to turn their attention to class-based models of cities and their contexts, the impact of colonialism on cities, and their integration into a worldwide economic system. As a result, Urban Anthropology became more integrated into the discourse of the other social sciences, and urban anthropologists cited non-anthropological works more frequently and with less hesitation (1996:1341)."

Thus the contemporary Urban Anthropology has become much inclusive and integrated whereby it has been characterizing the holistic nature of Anthropology when applied to the urban sphere. Its domain is so widened and evolved that now urban anthropologists have been able to raise their insights into a broad range of human issues from cities. They are not only confined to local, isolated communities only as their active engagement is on the study of cross-cultural comparison of communities within regional, national and international level.

\section{PROSPECTS OF URBAN ANTHROPOLOGY IN NEPAL}

Researches on Urban Anthropology in any country can be done in two ways: by examining the types of cities or examining the various sociocultural issues within the cities. These two methods are overlapping and dependent of each other. By defining different types of cities, one would use social factors as well as economic and political factors to compare and categorize the cities. By directly looking at the different socio-cultural issues, one would also be studying how they affect the intra-city dynamics. Urban Anthropology is its least developed stage in Nepal. But, it has an excellent prospect in Nepal. Nepalese cities possess a number of issues that can be quite relevant for Urban Anthropology. The prospect of this sub-field in Nepal can be explained as follow: 
1. Comparative Study of Nepal's Emerging Cities: Using the tradition and concept of Anthropology of the City, one can assume the comparative study of Nepal's emerging cities in terms of socio-cultural, economic, political and other aspects related to socio-cultural life. Following this tradition, Nepalese cities could be theorized using a number of metaphors such as Sacred City, Industrial City, Gendered City and so on as Low (1996) exemplifies.

2. Study of Intra-City Dynamics: In the other way, early urban anthropologists were actively engaged in documenting urban ethnography which can be very useful in the context of Nepalese cities, too. Likewise, issues such as caste/ethnicity in Nepalese cities, labor and immigration, gender issues, family life and kinship networks in these cities, urban poverty which is believed to be a problem arises out of urbanism, migrant adaptation, neighborhood etc. can be great inputs for urban anthropologists. Similarly, community studies, contemporary urban issues like urban class structure, religion, gender issues, slum dwellers' problems, etc. would be equally productive issues for urban anthropologists.

3. Urban Planning and Policy Debates: Urbanization in Nepal is so far a loosely treated concept and process. It has largely remained unmanaged, unplanned and unscientific. Ertur (1994:20) is quite right in identifying it who argues that within the development context of Nepal, the concept of "urbanization" is a misunderstood, as well as misinterpreted, process. Urbanization in Nepal has to be an important and wellemphasized development agenda. As Sharma remarks "Nepal remains one of the least urbanized countries in the world and also in South Asia. While this low level of urbanization is a matter of considerable concern for the economic development of the country, the present state of urbanization and urban development also manifests distinctive characteristics and problems that demand urgent attention. (2003:375)."

So, in our context overcoming the problems given by unplanned 
Urban Anthropology...... Bhandari

urbanization by utilizing the opportunities given by urbanization should be the utmost priority at the current period. However so far in our context, problems caused by the urbanization process have weighed much heavier in comparison to the possible opportunities and prospects that may be beneficial for the betterment of people and for uplifting their quality of living standard. Urban Anthropology can be effective in urban planning and solution of a variety of problems associated with urbanization. Here, recalling Low is quite significant who asserts that Stack (1996), Bourgois (1995), Susser (1991) and Newmann (1992) argue that while anthropological data are essential to understating urban problems, anthropologists have hesitated to participate in urban public policy debates (1996:384). This is particularly true for the case of mainstream Anthropology and anthropologists of Nepal who are yet to cast a prominent mark on Nepalese urban policy debates. More or their less apathetic nature has been the utmost challenge for this subfield of Socio-cultural Anthropology itself. This is particularly true in the sense that available dominant literatures on cities and urbanization in Nepal are hardly from anthropologists. It is they who can contribute the most and the best in the development of the field of Urban Anthropology in Nepal.

\section{CONCLUSION}

Urbanization represents the latest stage of civilization at least theoretically. Cities are considered as relatively recent development of human culture made possible by a stable food supply. Almost everywhere in the world, people are moving from the rural area to towns and cities. This rural-urban migration is happening so fast that the various agencies that monitor such movements cannot agree on the pace. Most scholars agree that the world will be predominantly urban in the $21^{\text {st }}$ century.

Despite being labeled as the study of primitive society, Anthropology started studying cities and urban life formally after the 1950s. In fact, the term Urban Anthropology appeared as a subfield of Socio-cultural Anthropology in the 1960s, while anthropologists had been conducting researches in cities much before this. This is an emerging subfield of Anthropology which has already seen an attraction of a number of 
scholars towards it in various parts across the globe. Already a number of anthropologists have established themselves as urban scholars and researchers and hence have broadened the horizon of Anthropology and strengthened the scope of the discipline in the urban context too. Urban Anthropology may offer a number of prospects for an urbanizing country like Nepal. Nepalese cities can offer a variety of inputs to Urban Anthropology but so far the gains have been cipher. Nepalese anthropologists to date have not been able to lay the foundation of the subfield in Nepal yet. They seem to be hesitant or even apathetic towards this sub-field so far. But if we are to catch or match the world trend, we must accomplish this task sooner or later so I do not see any reason to delay in this regard.

\section{REFERENCES}

Al-Zubaidi, Layla. (N.D.) Urban Anthropology - An Overview Retrieved at http://www.indiana.edu/ wanthro/URBAN.htm

Angelini, Alessandro. (2009). Urban Anthropology in Encyclopedia of Urban Studies. Retrieved April 14, 2010, from http:// www.sage-ereference.com/urbanstudies/Article_n297. html

Basham, Richard. (1978). Urban Anthropology, the Cross-Cultural Study of Complex Societies. Palo Alto, CA: Mayfield Publishing Company

CBS (2003). Population Monograph of Nepal, Kathmandu: CBS, HMG/ Nepal.

Champion, Tony. (2001). "Urbanization, Suburbanization, Counterurbanization and Reurbanization." Handbook of Urban Studies. SAGE Publications. Retrieved 14 Apr. 2010. <http://www.sage-ereference.com/hdbk_urban/ Article_n9.html>.

Ertur, Omer. (1994). "The Need for a National Urbanization Policy in Nepal" in Asia-Pacific Population Journal, Vol. 9, No. 3, September 1994, pp. 19-36

Hannerz, U. (1980). Exploring the City: Inquiries toward an Urban Anthropology, New York: Columbia University Press

Kemper, Robert V., and Jack Rollwagen (1995) “Urban Anthropology”. In 
Urban Anthropology...... Bhandari

Encyclopedia of Cultural Anthropology. Ember, Melvin,

David Levinson, eds. Lakeville: American Reference Publishing

Kumar, M. Satish. (2003). "Urbanization." in Encyclopedia of Community. SAGE Publications. Retrieved 10 May. 2010. <http:// WwW.sage-ereference.com/community/Article_n502. html>.

Lewis, Oscar. (1968). La Vida: A Puerto Rican Family in the Culture of Poverty. San Juan and New York: Vintage Books.

Low, Setha M. (1996). "The Anthropology of Cities: Imagining and Theorizing the City" in Annual Review of Anthropology, Vol. 25, pp. 383-409 http://www.jstor.org/stable/2155832

Portnov, Boris A., Madhav Adhikari and Moshe Schwartz. (2007). "Urban Growth in Nepal: Does Location Matter?" in Urban Studies, Vol. 44, Nos. 5/6, pp. 915-937, http://usj. sagepub.com/content/44/5-6/915

Redfield, Robert. (1947). "The Folk Society," in American Journal of Sociology, Vol.52 January 1947, pp. 293-308.

Roger Sanjek. (1996). "Urban Anthropology" in the Encyclopedia of Social and Cultural Anthropology http://www.bookrags. com/tandf/urban-anthropology-tf/

Sharma, P. (2003). "Urbanization and Development" in Population Monograph of Nepal, Volume I, NPC Secretariat, HMG, and CBS, Kathmandu Nepal, pp. 375-412

Smart, Alan, and Josephine Smart. (2003). "Urbanization and the Global Perspective" in Annual Review of Anthropology, Vol. 32 (2003), pp. 263-285 http://www.jstor.org/stable/25064830

Wirth, Louis. (1938). "Urbanism as a Way of Life" in American Journal of Sociology Vol. 44, pp. 1-24. 